\title{
Analysis of the N Protein Sequence Variability in 13 Isolated PRRSV Strains from China
}

\author{
Yang Xia ${ }^{*}$, Baodan Huang ${ }^{*}$, Bin $\mathrm{Wu}^{2}$, Yi Zhang1, Maole Yan ${ }^{1}$, Yan Li ${ }^{1 \#, ~ J i d a ~ L i 1 " ~}$ \\ ${ }^{1}$ Institute of Zoonosis, College of Public Health, Zunyi Medical University, Zunyi, China \\ ${ }^{2}$ Shijiazhuang No. 4 Pharmaceutical Co, Ltd, Shijiazhuang, China \\ Email: "liyan067321@sina.com, "lijida198485@163.com
}

How to cite this paper: Xia, Y., Huang, B.D., Wu, B., Zhang, Y., Yan, M.L., Li, Y. and Li, J.D. (2021) Analysis of the N Protein Sequence Variability in 13 Isolated PRRSV Strains from China. Journal of Biosciences and Medicines, 9, 63-75. https://doi.org/10.4236/jbm.2021.92007

Received: December 18, 2020

Accepted: February 20, 2021

Published: February 23, 2021

Copyright $\odot 2021$ by author(s) and Scientific Research Publishing Inc. This work is licensed under the Creative Commons Attribution International License (CC BY 4.0).

http://creativecommons.org/licenses/by/4.0/

\begin{abstract}
Object: To analyze porcine reproductive and respiratory syndrome virus (PRRSV) strains from 13 infection cases via the $\mathrm{N}$ protein gene and its encoded amino acid sequence and to provide a theoretical basis for the epidemiological study, prevention and control of porcine reproductive and respiratory syndrome (PRRS). Methods: In clinically suspected PRRSV infections, viruses were isolated by extracting viral nucleic acid and amplifying the $\mathrm{N}$ protein gene by RT-PCR. Then, the product was purified and sequenced to acquire the whole gene sequence of the $\mathrm{N}$ protein and its encoded amino acid sequence. DNASTAR software was used to analyze the homology, the genetic evolution and the derivation of the variability of amino acids of the $\mathrm{N}$ protein gene from 13 PRRSV strains and classical domestic and foreign strains. Results: Among the thirteen strains of PRRSV isolated from this study, ten strains had the greatest homology with the JXA1 strain $(98.9 \%-100 \%)$, and they belonged to the sublineage 8.7. The remaining three strains had the greatest homology with the NADC30 strain $(95.4 \%-97.1 \%)$, and they belonged to lineage one. The analysis of the variability of $\mathrm{N}$ protein amino acids showed that there were high frequency mutations in the five loci of 13 isolated strains of PRRSV as follows: 15th amino acid (10/13), 46th amino acid (11/13), 91st amino acid (10/13), 109th amino acid (10/13), and 117th amino acid (10/13). Conclusion: In recent years, sublineage 8.7 was the dominant pedigree in field PRRSV epidemic strains in China with lineage one occupying a certain proportion of the field. Four high frequency mutations existed in $\mathrm{N}$ protein antigen epitopes of isolated strains from the region. The nuclear localization signal (NLS) structure, specifically the $46^{\text {th }}$ amino acid residue of the $\mathrm{N}$ protein, was mutated and genetically stable.
\end{abstract}

*These authors contributed equally to this work and should be considered as first authors.

\#Corresponding authors. 


\section{Keywords}

PRRSV, Nucleocapsid Protein, Nuclear Location Signal, Epidemiological, Amino Acid Sequence

\section{Introduction}

Caused by the porcine reproductive and respiratory syndrome virus (PRRSV), porcine reproductive and respiratory syndrome (PRRS) is one of the major infectious swine diseases. This disease was reported to have initially emerged in the United States [1]; thereafter, it appeared in many countries, such as Canada, France, German, Britain, the Netherlands, Belgium, Spain, Japan, the Philippines, and Australia [2]. In 1996, Guo Baoqing et al. initially isolated the porcine reproductive and respiratory syndrome virus (PRRSV) from an aborted fetus and hence confirmed the prevalence of porcine reproductive and respiratory syndrome (PRRS) in China [3]. In 2006, an epidemic characterized by high fever, rubefaction and dyspnea emerged in swine farms in most areas of China. Later, this epidemic was confirmed to have been caused by a PRRSV variant strain and was denominated as highly pathogenic porcine reproductive and respiratory syndrome (HP-PRRS) because of its high morbidity [4]. The outbreak of HP-PRRS caused mass mortality of the swine and huge economic losses for swine farms. Considering that the economic loss caused by HP-PRRS is far greater than that of type A infectious disease, PRRS was classified as type B infectious disease by the Office International Des Epizooties (OIE) in 1992. In addition, in 2008, in the revised "first, second or third category of animal disease species list" in China, HP-PRRS was listed in the first category of animal diseases. Although HP-PRRS was effectively controlled with the successful development and application of inactivated and attenuated vaccines, due to an excessive fear of HP-PRRS, vaccines, especially attenuated vaccines, are abused. As Yang Hanchun, a professor of the China Agricultural University, says, "it is quite hard to find PRRS-negative swine farms in China." This study shows that since the outbreak of HP-PRRS in 2006, domestic PRRSV isolates belong to highly pathogenic porcine reproductive and respiratory syndrome virus branches with a very high homology [5]. Whether these isolates are from the vaccine virus is unknown, but it can be speculated that the field of PRRSV may be facing a new round of selection pressure, so maintaining epidemiological tracking of the field PRRSV-isolated strains is quite significant for the prevention and control of the disease.

PRRSV belongs to the arterial inflammation virus division and is one of the Arteritis viruses. It is spherical or oval under the electron microscope with a particle diameter of 50 - $65 \mathrm{~nm}$ and has a cystic membrane structure with a superficial surface. PRRSV is a positive-sense, single-stranded RNA virus with no segment and cystic membrane. With a length of $15 \mathrm{~kb}$, the PRRSV genome contains 
10 open reading frames (ORF), ORF1A, ORF1B, ORF2, ORF2A, ORF3-ORF5, ORF5a, ORF6 and ORF7. Each reading code frame of the viral genome partially overlaps with the adjacent reading code frame [6]. The nucleocapsid protein is the only protein that makes up all the capsid of the virus. Encoded by ORF7, the PRRSV N protein is approximately $372 \mathrm{bp}$ in length and approximately $15 \mathrm{kD}$ in width, and without $\mathrm{N}$-glycosylation, it is a nonglycosylated protein. The genetic evolution tree was established on the basis of the whole gene, and the genetic evolution tree based on the ORF7 gene is the most closely inherited; thus, ORF7 is considered to be a marker gene capable of genetic expression of PRRSV information [7]. Rich in antigenic epitopes and with the greatest expression in all PRRSV proteins, the $\mathrm{N}$ protein can induce the expression of the body IL-10, and thereby, it can enhance the immune evasion ability of the virus [8]. Compared with the classical PRRSV strains, HP-PRRSV causes more CD4 + CD25 + FOXP3 + T cell-specific response, which is closely related to mutations in the $46^{\text {th }}$ amino acid of the HP-PRRSV N protein [9]. Based on the significance of the $\mathrm{N}$ protein in the epidemiological investigation of PRRSV and the immunological significance of antigenic epitopes in resisting the defense from the body, this study analyzed the sequence of the $\mathrm{N}$ protein and its variability in 13 strains of PRRSV isolated from fields in Shandong and Liaoning provinces in China. The results provide the basis for the epidemiological analysis of PRRSV and establish the basis for the functional study of $\mathrm{N}$ protein antigen epitopes, which will be beneficial for the prevention and control of PRRSV.

\section{Materials and Methods}

\subsection{Isolation and Identification of Virus}

All 13 strains of the virus were inoculated in Marc-145 cells in this laboratory (our experiment was approved by the Animal Ethics Committee of Zunyi Medical University); this method of isolates was described in the paper which was published in virus genes by our research group [10]. By Reverse Transcription-Polymerase Chain Reaction (RT-PCR) identification, the 13 strains were identified as PRRSV. Details of the strains are shown in Table 1.

\subsection{Primer}

Referring to a series of primers published by this project group, the synthesis of one pair of primers amplified the ORF7 gene. The primers used in this study are shown in Table 2.

\subsection{Target Gene cDNA Acquisition}

Viral RNA was extracted by the acid phenol-thiocyanate-chloroform method, and the target gene was amplified by RT-PCR. Then, the acquired target gene was connected with the PMD18-T carrier and transformed into JM109 sensory E. coli cells. The bacterium liquid identified by Polymerase Chain Reaction (PCR) was sent to the Dalian Bao Biological Company for sequencing. 
Table 1. Viruses in this study.

\begin{tabular}{cccc}
\hline Serial Number & Name of the Poison Plant & Time and Place of Separation & Separation Organs \\
\hline 1 & sdaq01 & 16040 Shandong Province & Lung \\
2 & sdlz02 & 160528 Shandong Province & Lung \\
3 & sdc103 & 160306 Shandong Province & Lung \\
4 & sdzb04 & 160320 Shandong Province & Lung \\
5 & sdcl05 & 161202 Shandong Province & Lung \\
6 & sdaq06 & 160413 Shandong Province & Lung \\
7 & sdlq08 & 161202 Shandong Province & Lung \\
8 & sdsg09 & 160326 Shandong Province & Lung \\
9 & sdsg10 & 161202 Shandong Province & Lung \\
10 & sdxt11 & 160327 Shandong Province & Lung \\
11 & $\operatorname{lnzd01}$ & 161202 Liaoning Province & Lung \\
12 & $\operatorname{lnzd02}$ & 161202 Liaoning Province & Lung \\
13 & $\operatorname{lnzd03}$ & 161202 Liaoning Province & Lung \\
\hline
\end{tabular}

Table 2. The sequence of primers in the research [10].

\begin{tabular}{cc}
\hline & primer \\
\hline Primer1 & 5'-GCCCCTGCCCACCACG-3' \\
Primer2 & 5'-TCGCCCTAATTGAATAGGT-3' \\
\hline
\end{tabular}

\subsection{Sequence Analysis}

With the help of DNASTAR analysis software, the ORF7 gene and its deduced amino acid sequence from each strain in this study were compared by the Jotun Hein method. The foreign reference strains in this study include the classical American strain VR-2332, the European classical strain Lelystad, the vaccine strain MLV, and the domestic reference strains are CH-1A, CH-1r, R98, JXA1 and 11 strains of PRRSV isolated by this laboratory in 2008 .

\section{Experimental Results}

\subsection{PCR Amplification of Target Gene cDNA}

As shown in Figure 1, we amplified the ORF7 gene from 13 strains of PRRSV by RT-PCR, and all of which had a $660 \mathrm{bp}$ or so band, which corresponds to the expected size.

\subsection{Nucleotide Sequence Analysis of the ORF7 Gene}

Sequencing results (all nucleotide sequences and amino acid sequences were submitted to GenBank (numbers: mg922935 - mg922947). To eliminate redundant sequences, the results of Table 3 were obtained by using DNASTAR software to compare the whole gene sequences of 13 strains of PRRSV isolates with 


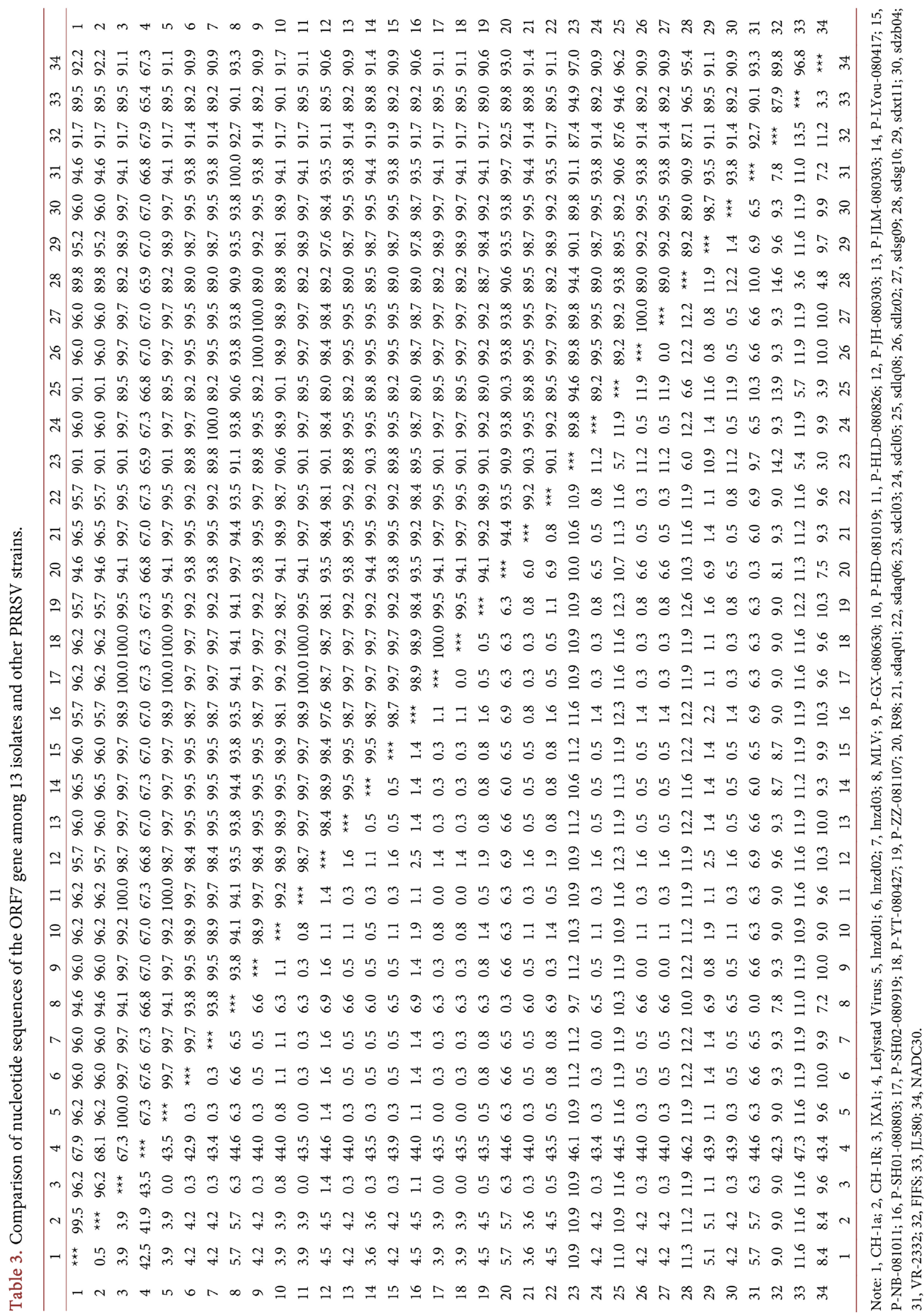




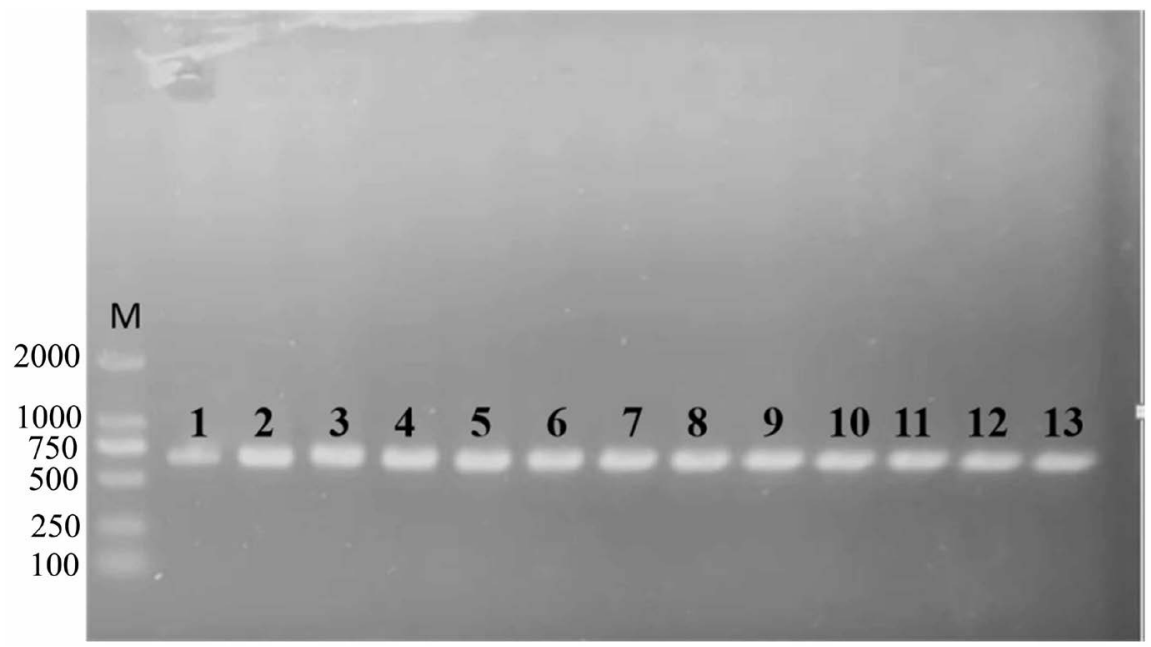

Figure 1. Results of amplification of the ORF7 gene in 13 isolates of PRRSV strains with RT-PCR. M: Marker DL2000; 1 - 13: Results of the amplification of the ORF7 gene from 13 isolates.

21 strains of American PRRSV N protein genes selected in GenBank. The sequencing results showed that the ORF7 gene from 13 strains of PRRSV did not have a base deletion or insertion in comparison with the traditional strains, and the gene mutations were in the partial sites. The homology of the ORF7 genes with the highly pathogenic PRRSV strains isolated from the domestic was $88.7 \%$ - $100 \%$ with the JXA1 strain, $87.1 \%$ - $91.7 \%$ with the FJFS strain, $89.3 \%-97.1 \%$ with the NADC30 and JL58 strains, $89.2 \%-96.5 \%$ with the classical strains $\mathrm{CH}-1 \mathrm{a}$ and $\mathrm{CH}-1 \mathrm{R}$ strains isolated from China, $89.5 \%-94.4 \%$ with the vaccine MLV strain, 89.5\% - 94.4\% with the American standard VR-2332 strain, 89.2\% 94.4\% with the classical R98 strain, 55.6\% - 58.3\% with the European classical Lelystad strain, and $88.2 \%-100 \%$ with the 11 previously isolated PRRSV strains. The internal homology of 13 isolated strains isolated was $88.4 \%-100 \%$. DNASTAR software was used to draw the genetic evolution tree (Figure 2) of the ORF7 gene from the isolated strains. The figure shows that the strains of PRRSV isolated from this experiment belong to the American strain (red mark), and the isolates are divided into two branches. Among them, sdcl03, sdlq08, and sdsg 10 and a pedigree represented by the NADC30 strain make up a branch, and the remaining 10 strains belong to a pedigree branch represented by the JXA1 strain.

\subsection{Analysis of Amino Acid Sequences Derived from the ORF7 Gene}

After the sequence of nucleic acid sequencing was removed, the DNA sequencing results were translated by Primer 5.0 software (amino acid sequence was submitted to GenBank as numbers mg922935 - mg922947). The results showed that the ORF7 gene of 13 isolated strains of PRRSV contains a complete open reading frame, and the coding area consisted of $372 \mathrm{bp}$ and encoded 123 amino acids. The DNASTAR software was used to compare the homology of the 13 


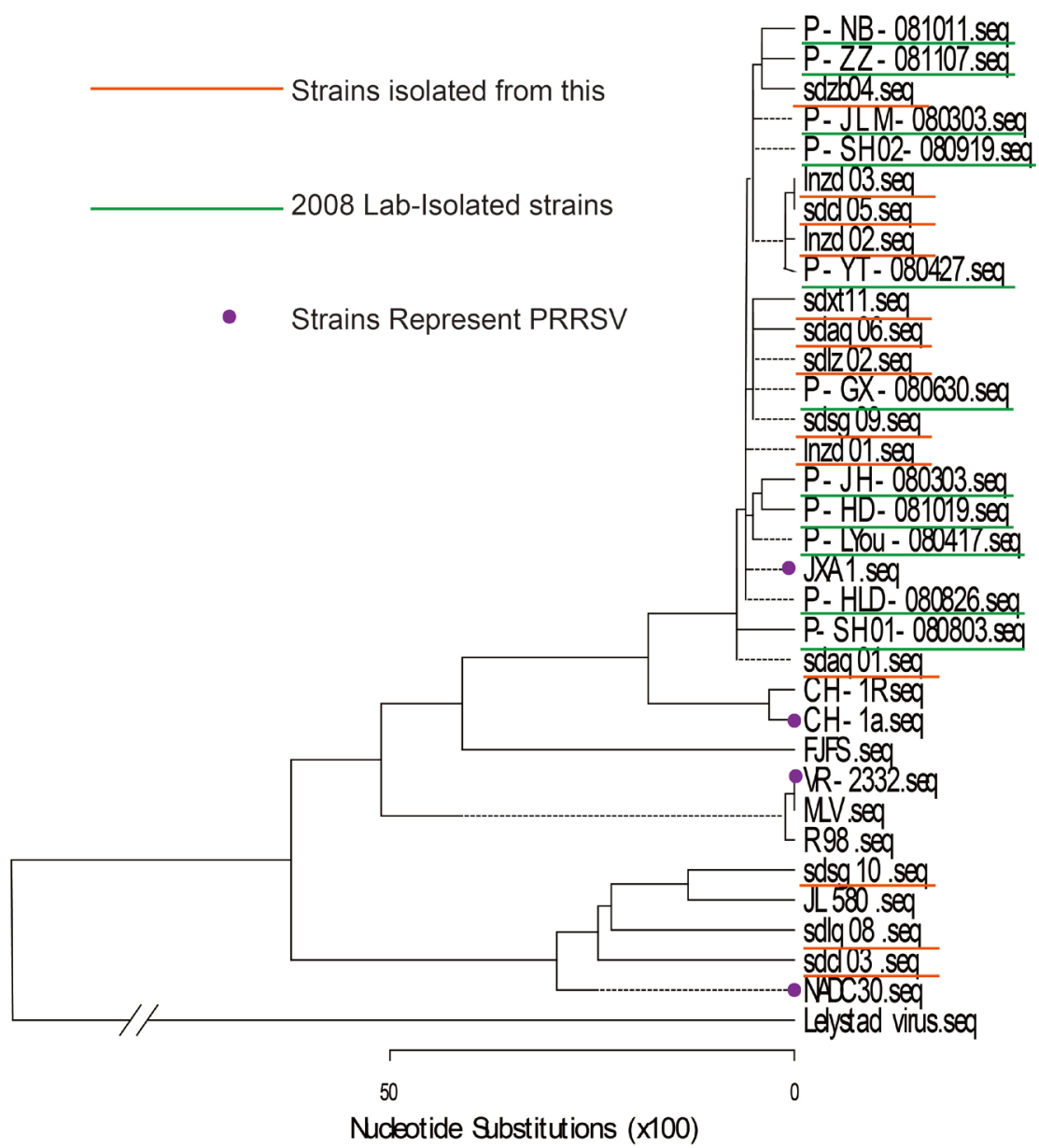

Figure 2. Phylogenetic tree of the ORF7 gene from 13 isolates of PRRS.

isolated strains of PRRSV with the amino acid sequence of domestic and foreign strains (see Table 4). The homology of the ORF7 gene with the highly pathogenic PRRSV strains isolated from the domestic JXA1 strain was $88.7 \%-100 \%$, and $87.1 \%-91.7 \%$ with the FJFS strain, $89.3 \%-97.1 \%$ with the NADC30 and JL58 strains, $89.2 \%$ - 96.5\% with the classical CH-1a and CH-1R strains isolated from China, $89.5 \%$ - 94.4\% with the MLV vaccine strain, $89.5 \%$ - 94.4\% with the American standard VR-2332 strain, 89.2\% - 94.4\% with the classical R98 strain, $55.6 \%-58.3 \%$ with the European classical Lelystad strain, $88.2 \%$ - 100\% with the 11 previously isolated PRRSV strains. The internal homology of 13 isolated viral strains isolated was $88.4 \%-100 \%$. Through DNASTAR software, the 13 isolated strains of PRRSV were compared with the amino acid sequences of the domestic and foreign strains (as shown in Table 4); as a whole, there were no deletions or insertions of amino acids in the isolates, and there was a point mutation in some sites. Compared with the classical domestic and foreign strains of $\mathrm{CH}-1 \mathrm{a}, \mathrm{CH}-1 \mathrm{R}$, VR-2332, MLV and R98 domestic and foreign (Figure 3), the 15th amino acid of the isolates (10/13) was mutated from D (aspartic acid) to $\mathrm{N}$ (asparagine), the 46th amino acid of the isolates (11/13) was mutated from K (lysine) to R (arginine), the $91^{\text {st }}$ amino acid of the isolates (10/13) was mutated from $\mathrm{T}$ (threonine) 
- $\rightarrow$ m แ

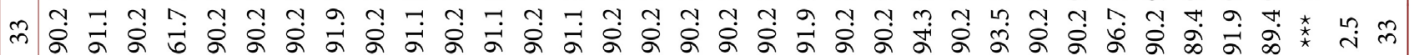

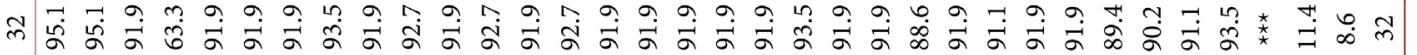
m

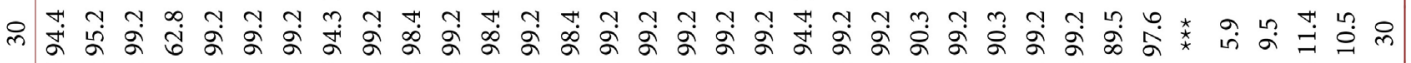

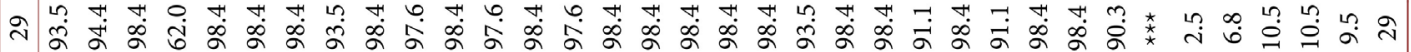
শి त ㄴ थ H ๗ नु न न ส च ते

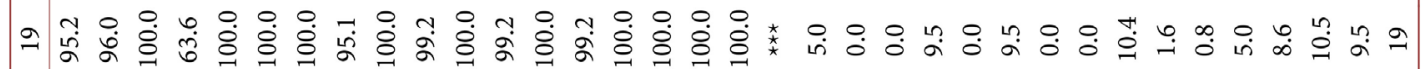
隹 숭

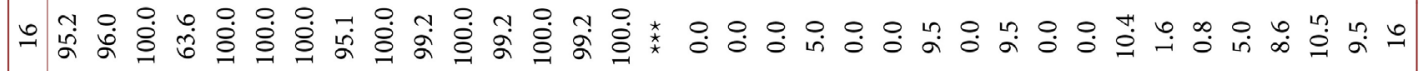
$n$ 눙 サ $=$ 숭

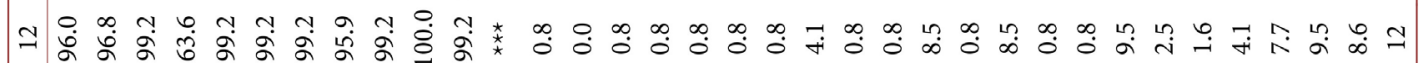

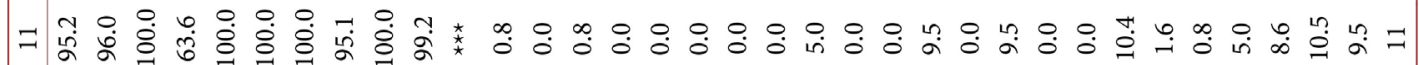

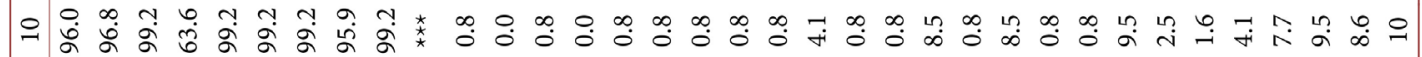

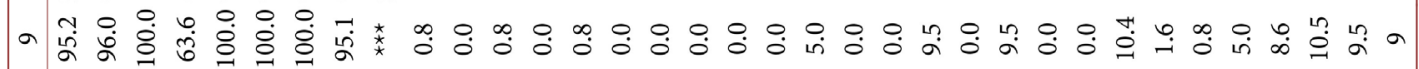

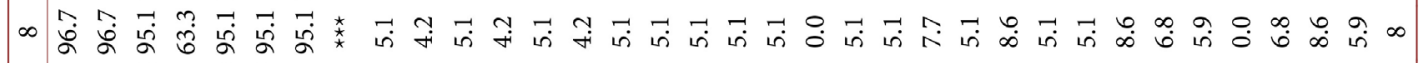

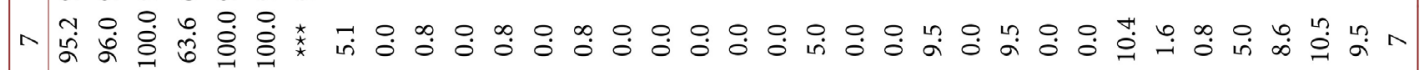

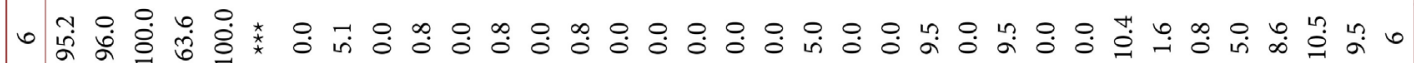

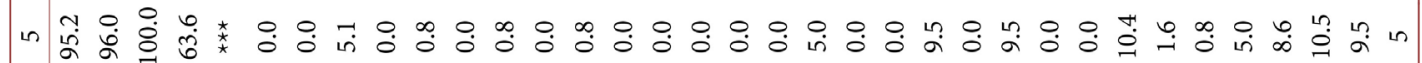

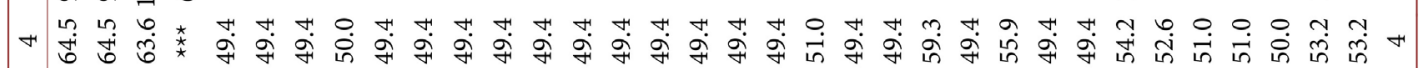

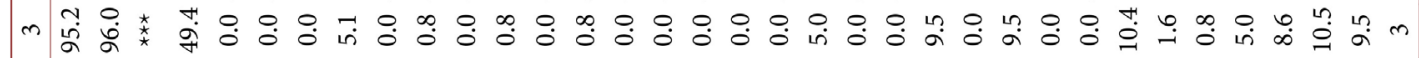

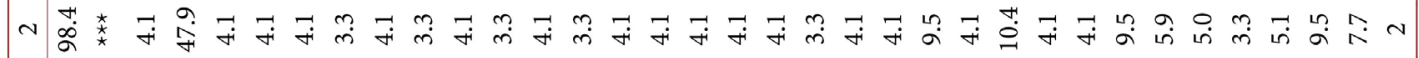

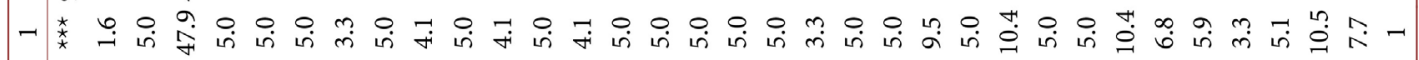
- $\mathrm{n}$ m 


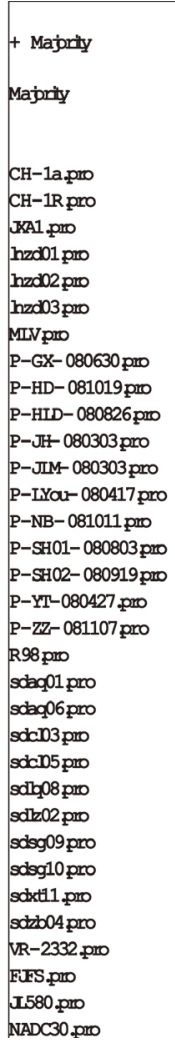

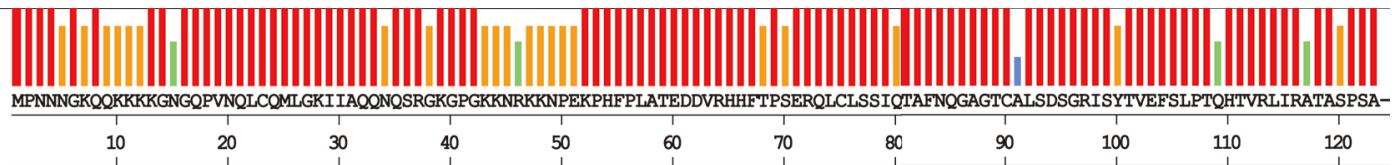

MPNNNGKOPKKKKKGNGQPVNQLCOMLGKIIAQQNQSRGKGPGKKNKKKKSSPEKPHFPLATEDDVRHHFTPSERQLCLSSI ITAFNQGAGTCTLSDSGRISYTVEFSLPTHHTVRLIRV IASPSA MPNNNGKQQKKKKGNGQPVNQLCQMLGKIIAQQNQSRGKGPGKKNNKKSPEKPHFPLATEDDVRHHFTPSERQLCLSSIDTAFNQGAGTCTLSDSGRISYTVEFSLPTHHTVRLIRVTASPSA . MPNNNGKOOKKKKKGNGOPVNOLCOMLGKIIAOONOSRGKGPGKKNRKKNPEKPHFPLATEDDVRHHFTPSEROLCLSSIOTAFNOGAGTCALSDSGRISYTVEFSLPTOHTVRLIRATASPSA . MPNNNGKQQKKKKGNGQPVNQLCOMLGKIIAQQNQSRGKGPGKKNRKKNPEKPHFPLATEDDVRHHFTPSERQLCLSSIQTAFNQGAGTCALSDSGRISYTVEFSLPTQHTVRLIRATASPSA. MPNNNGKQQKKKKGNGQPVNQLCQMLGKIIAQQNQSRGKGPGKKNRKKNPEKPHFPLATEDDVRHHFTPSERQLCLSSIQTAFNQGAGTCALSDSGRISYTVEFSLPTQHTVRLIRATASPSA MPNNNGKQQKKKKKGNGPVNQLCOMLGKIIAQQNQSRGKGPGKKNRKKNPEKPHFPLATEDDVRHHFTPSERQLCLSSI IAAFNGAGTCALSDSGRISYTVEFSLPTOHTVRLIRATASPSA MPNNNGKQQKRKKGDGQPVNQLCQMLGKIIAQQNQSRGKGPGKKNGKKKNPEKPHFPLATEDDVRHHFTPSERQLCLSSI ITAFNQGAGTCILSDSGRISYTVEFSLPTHHTVRLIRVTASPSA MPNNNGKOOKKKKKGNGOPVNOLCOMLGKTIAOONOSRGKGPGKKNRKKNPFKPHFPLATEDDVRHHFTPSEROLCLSSIOTAFNOGAGTCALSDSGRISYTVEFSLPTOHTVRLIRATASPSA . MPNNNGKQQKKKKGNGQPVNQLCQMLGKIIAQQNQSRGKGPGKKNRKKNPEKPHFPLATEDDVRHHFTPSERQLCLSSIQTAFNQGAGTCIILSDSGRISYTVEFSLPTQHTVRLIRATASPSA . MPNNNGKQQKKKKGNGQPVNQLCQMLGKIIAQQNQSRGKGPGKKNRKKNPEKPHFPLATEDDVRHHFTPSERQLCLSSICTAFNQGAGTCALSDSGRISYTVEFSLPTQHTVRLIRATASPSA. MPNNNGKQQKKKKGNGQPVNQLCOMLGKIIAQQNQSRGKGPGKKNRKKNPEKPHFPLATEDDVRHHFTPSERQLCLSSIQTAFNQGAGTCULLSDSGRISYTVEFSLPTQHTVRLIRATASPSA MPNNNGKOOKKKKKGNGQPVNOLCOMLGKIIAOONOSRGKGPGKKNRKKNPEKPHFPLATEDDVRHHFTPSEROLCLSSIOTAFNOGAGTCALSDSGRISYTVEFSLPTOHTVRLIRATASPSA. MPNNNGKQQKKKKGNGQPVNQLCOMLGKIIAQQNQSRGKGPGKKNRKKNPEKPHFPLATEDDVRHHFTPSERQLCLSSI TTAFNQGAGTCIILSDSGRISYTVEFSLPTQHTVRLIRATASPSA

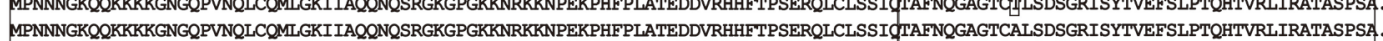
MPNNNGKQQKKKKGNGQPVNQLCOMLGKIIAQQNQSRGKGPGKKNRKKNPEKPHFPLATEDDVRHHFTPSERQLCLSSI DTAFNQGAGTCALSDSGRISYTVEFSLPTQHTVRLIRATASPSA MPNNNGKQQKKKKKGNGQPVNQLCQMLGKIIAQQNQSRGKGPGKKNRKKNPEKPHFPLATEDDVRHHFTPSERQLCLSSIDTAFNQGAGTCALSDSGRISYTVEFSLPTQHTVRLIRATASPSA MPNNNGKOOKKKKKGNGOPVNOLCOMLGKIIAOONOSRGKGPGKKNRKKNPEKPHFPLATEDDVRHHFTPSEROLCLSSIOTAFNOGAGTCALSDSGRISYTVEFSLPTOHTVRLIRATASPSA MPNNNGKQQKKKKGNGQPVNQLCQMLGKIIAQQNQSRGKGPGKKNRKKNPEKPHFPLATEDDVRHHFTPSERQLCLSSIQTAFNQGAGTCALSDSGRISYTVEFSLPTQHTVRLIRATASPSA MPNNNGKQQKRKKGDGQPVNQLCOMLGKIIAQQNQSRGKGPGKKNGKKKNPEKPHFPLATEDDVRHHFTPSERQLCLSSIOTAFNQGAGTCHILSDSGRISYTVEFSLPTIFHTVRLIRVTASPSA. MPNNNGKQQKKKKGNGQPVNQLCQMLGKIIAQQNQSRGKGPGKKNRKKNPEKPHFPLATEDDVRHHFTPSERQLCLSSIQTAFNQGAGTCALSDSGRISYTVEFSLPTQHTVRLIRATASPSA. MPNNNGKOOKKKKKGNGOPVNOLCOMLGKIIAOONOSRGKGPGKKNRKKNPEKPHFPLATEDDVRHHFTPSEROLCLSSIOTAFNOGAGTCALSDSGRISYTVEFSLPTOHTVRLIRATASPSA. MPNNNGKQQNKKKGDGQPVNQLCQMLGKIIAQQSSQSRGKGPGKRNKNRNIEKPHFPLATEDDVRHHFTPSERQLCLSSIRTAFNQGAGTCILSDSGRISYTVEFSLPTIHHTVRLIRATASPSA. MPNNNGKQQKKKKGNGQPVNQLCQMLGKIIAQQNQSRGKGPGKKNRKKNPEKPHFPLATEDDVRHHFTPSERQLCLSSI DTAFNQGAGTCALSDSGRISYTVEFSLPTQHTVRLIRATASPSA

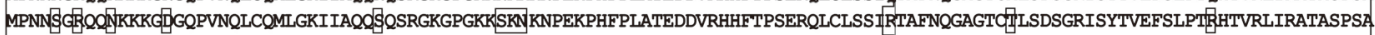
MPNNNGKOQKKKKGNGQPVNOLCOMLGKIIAQONOSRGKGPGKKNRKKNPEKPHFPLATEDDVRHHFTPSERQLCLSSIOTAFNOGAGTCALSDSGRISYTVEFSLPTOHTVRLIRATASPSA MPNNNGKOOKKKKKGNGOPVNOLCOMLGKIIAOONOSRGKGPGKKNRKKNPEKPHFPLATEDDVRHHFTPSEROLCLSSIOTAFNOGAGTCALSDSGRISYTVEFSLPTOHTVRLIRATASPSA

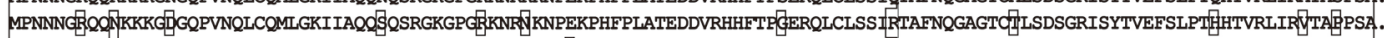
MPNNNGKQQQKKKKGNGQPVNQLCOMLGKIIAQQNQSRGKGPGKKNRKKNPGKPHFPLATEDDVRHHFTPSERQLCLSSI QTIAFNQGAGTCALSDSGRISYTVEFSLPTQHTVRLIRATASPSA MPNNNGKQQKKKKGNGQPVNQLCOMLGKIIAQQNQSRGKGPGKKNRKKNPEKPHFPLATEDDVRHHFSPSERQLCLSSIDTAFNQGAGTCALSDSGRISYTVEFSLPTQHTVRLIRATASPSA MPNNNGKOQKRKKGDGQPVNQLCOMLGKIIAQQNQSRGKGPGKKNRKKKNPEKPHFPLATEDDVRHHFTPSERQLCLSSIQTAFNQGAGTCTLSDSGRISYTVEFSLPTHHTVRLIRVIASPSA MPNNNGROOKKN KGNGOPVNOLCOMLGKIIAOONOSRARGPGKKSSKKKSPPEKPHFPLATEDDVRHHFTPSEROLCLSS IHTAFNOGAGTCTLSDSGRISYTVEFSLPTHHTVRLIRVIASPSA

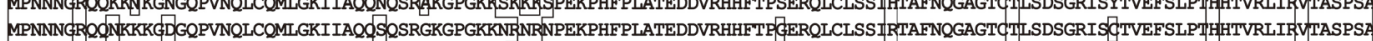
MPNNNGRQQNKKKGDGQPVNQLCOMLGKIIAQQSQSRGKGPGKKNKNRNPEKPHFPLATEDDVRHHFTPSERQLCLSSIRTAFNQGAGTCTLSDSGRISYTVEFSLPTHHTVRLIRVIASPSA

Figure 3. Comparison of the variability of the N protein from 13 PRRSV strains with domestic and foreign PRRSV strains.

to A (alanine), the 109th amino acid of the isolates (10/13) was mutated from $\mathrm{H}$ (histidine) to $\mathrm{Q}$ (glutamine), and the 117 th amino acid of the isolates $(12 / 13)$ was mutated from $\mathrm{V}$ (valine) to A (alanine).

\section{Discussion}

\subsection{The Significance of Homology and Epidemiology Analyses in Disease Prevention and Control}

According to the classification system established by M. shi et al., the epidemic strains of the American PRRSV, which was spread worldwide were divided into 9 lineages and 37 sublineages [11]. From the genetic evolution tree (Figure 2), 10 strains of the 13 strains isolated from this study belong to lineage 8 (sublineage 8.7), represented by $\mathrm{CH}-1 \mathrm{~A}$ and JXA1 strains. In addition, 11 strains of the virus we isolated in 2008 all belong to sublineage 8.7. In the past decade, sublineage 8.7 was the dominant pedigree in the epidemic field PRRSV strains in China, and this is consistent with the results observed by Zhang Chanping et al. [12]. Three strains of the virus isolated in this experiment belong to lineage one, which was represented by JL580 and NADC30 strains. As the PRRSV pedigree in China appeared and became a trend after 2013, lineage one occupies a certain proportion of the field. The results show that the prevalent strains of PRRSV in the field are still HP-PRRSV, and the field isolates are facing tremendous selective pressure. Whether lineage one represented by the NADC30 strain will 
present the trend of rising and become the dominant strains in the future is unknown. This virus needs to be illustrated by more epidemiological studies and data. Studies have confirmed that PRRSV can be transmitted over long distances through commercial pigs carrying a virus and with infectious semen [13]. In this study, SDCL05 and LNZD03 strains are from Shandong Province and Liaoning Province, respectively. The homology between these two strains is as high as $100 \%$. Although there is nearly a 1000 kilometer-distance between Liaoning Shandong provinces, viruses isolated from these two places are highly homologous. After further analysis of the background of the isolates, it was found that the semen of the pigs in these two places originated from the same place. This suggests that we should cautiously screen pathogens such as PRRSV while doing breed introducing. Sdsg09 and sdsg10 are two strains from the same city of Shandong Province, but their homology is only $89 \%$. This shows that different epidemic strains exist in the same region, so different vaccines should be selected during the immunization process.

\subsection{The Significance of the N Protein Gene and Its Encoded Amino Acid Sequence Variation in the Pathogenesis of Disease}

There is a point mutation in the nucleic acid sequence of the $\mathrm{N}$ protein gene. Comparing the results of homology of the derived amino acid sequences with the homology of nucleic acid sequences, the variation coefficient of the former is much lower than that of the latter. Therefore, nucleic acid mutations at individual sites did not cause changes in the corresponding amino acid sequences. The results showed that there are three highly mutated regions $(3-16,37-52,118$ 123) and three highly conserved regions (16 - 27, $51-69,81-90,102-106)$ in $\mathrm{N}$ protein amino acid sequences [14]. By analyzing the variability of domestic and foreign classical PRRSV strains (Figure 3), this study found that the high-frequency mutation sites of 13 strains of PRRSV isolates were located in at the $15^{\text {th }}$ amino acid (10/13), $46^{\text {th }}$ amino acid (11/13), 91 $1^{\text {st }}$ amino acid (10/13), $109^{\text {th }}$ amino acid (10/13), and $117^{\text {th }}$ amino acid (10/13). It is interesting to find that, in addition to the $46^{\text {th }}$ amino acid in the highly mutated region, the remaining four high-frequency mutations sites were not in the highly mutated region. For reference, the $\mathrm{N}$ protein of the American PRRS strains contains 5 important epitopes, which are located in the regions of $30-52,37-52,69-123$ [15]. The high frequency mutations of the 4 sites in this study were all located in the antigenic epitopes, but the effects on the immunogenicity of the PRRSV need further experimental verification. This study confirmed that the PRRSV $\mathrm{N}$ protein also contained two typical nuclear location signals (NLS); the single type NLS is located in the N protein at amino acids $10-13$, and the double type is located in the $\mathrm{N}$ protein at amino acids 41 47 [16]. The study revealed that the NLS-mediated protein nucleation was an important part of the information exchange of nuclear materials in intracellular signaling networks, and it plays a key role in cell proliferation, differentiation, regulation and transformation [17]. Most viral proteins entering the nucleus require nuclear transporter receptor protein importin $\alpha$ or importin $\beta$ to identify 
and bind to the NLS sequence carried by the target protein. The pathogenicity, virulence and replication ability of the virus are significantly affected by the mutation in the NLS structure and sequence carried by virus that enters into the nucleoprotein. For instance, Venezuelan equine encephalitis virus capsid protein helps to infect itself by inhibiting the synthesis of beta-interferon in host cells after it enters into the nucleus protein; therefore, when the nuclear protein NLS sequence is mutated, the virulence of the virus weakens significantly [18]. The dengue virus nonstructural protein 5 (NS5) plays a role in resisting the antiviral effects of host cells, including inhibition of the synthesis of target cells IL-8, and when the NS5 protein NLS sequence is mutated, virus replication capability decreases by nearly 1000 times [19]. The duration of virusemia in infected animals becomes shorter and the ability of neutralizing antibody increases markedly [20]. It was found in a previous study that, compared with the classical PRRSV strains, the N protein dual-type NLS structure of HP-PRRSV, which emerged in China in 2006, had a consistent mutation in the $46^{\text {th }}$ amino acid (K46 was replaced by R46) [10]. This study showed that among the 13 strains of PRRSV field isolates, there were 11 strains whose $46^{\text {th }}$ amino acid mutations in their $\mathrm{N}$ protein are arginine. In that previous study, our subjects were strains isolated from 2007-2009, and this research isolated PRRSV strains from 2015-2016. Combining the PRRSV strains published in 2010-2014 by GenBank, we speculate that the mutation at the $46^{\text {th }}$ amino acid $(\mathrm{K} 46 \rightarrow \mathrm{R} 46)$ in the $\mathrm{N}$ protein dual-type NLS structure has been stably inherited since the outbreak of HP-PRRSV. Studies have been conducted on the mutation of this locus from the perspective of immunology, and the mutation of this locus can cause the host cell to produce more CD $4+\mathrm{CD} 25+$ FOXP3 + T-cell specific responses during the process of virus infection, thus benefiting the immune evasion of the virus [9]. However, there is no research conducted from the perspective of the nucleoprotein (the "duty" of NLS structure) to explain the response to this mutation at this locus.

\section{Author's Contributions}

$\mathrm{YX}$ and $\mathrm{BH}$ carried out most of the experiments and wrote the manuscript. MY, $\mathrm{BW}, \mathrm{YZ}$ participated in the planning of the project. JL and YL conceived of the study and participated in its design and coordination. All authors read and approved the final manuscript.

\section{Acknowledgements}

Financial support for this study was obtained from the National Natural Science Foundation of China (Grant number 31860692), Scientific and Technological Project of Guizhou Province (Grant number Qian Ke He Ji Chu [2016]1166).

\section{Conflicts of Interest}

The authors declare no conflicts of interest regarding the publication of this paper. 


\section{References}

[1] Bilodeau, R., Dea, S., Sauvageau, R.A. and Martineau, G.P. (1991) "Porcine Reproductive and Respiratory Syndrome" in Quebec. Veterinary Record, 129, 102-103. https://doi.org/10.1136/vr.129.5.102

[2] Zimmerman, J.J., Yoon, K.J., Pirtle, E.C., Wills, R.W., Sanderson, T.J. and McGinley, M.J. (1997) Studies of Porcine Reproductive and Respiratory Syndrome (PRRS) Virus Infection in Avian Species. Veterinary Microbiology, 55, 329-336. https://doi.org/10.1016/S0378-1135(96)01320-X

[3] Guo, B.Q., Chen, Z.S., Liu, W.X. and Cui, Y.Z. (1996) Isolation and Identification of Porcine Reproductive and Respiratory Syndrome (PRRS) Virus from Aborted Fetuses Suspected of PRRS. Chinese Journal of Preventive Veterinary Medicine, No. 2, 3-7.

[4] Tian, K., Yu, X., Zhao, T., Feng, Y., Cao, Z., Wang, C., Hu, Y., Chen, X., Hu, D., Tian, X., Liu, D., Zhang, S., Deng, X., Ding, Y., Yang, L., Zhang, Y., Xiao, H., Qiao, M., Wang, B., Hou, L., Wang, X., Yang, X., Kang, L., Sun, M., Jin, P., Wang, S., Kitamura, Y., Yan, J. and Gao, G.F. (2007) Emergence of Fatal PRRSV Variants: Unparalleled Outbreaks of Atypical PRRS in China and Molecular Dissection of the Unique Hallmark. PLOS ONE, 2, e526.

https://doi.org/10.1371/journal.pone.0000526

[5] Yu, X., Chen, N., Wang, L., Wu, J., Zhou, Z., Ni, J., Li, X., Zhai, X., Shi, J. and Tian, K. (2012) New Genomic Characteristics of Highly Pathogenic Porcine Reproductive and Respiratory Syndrome Viruses Do Not Lead to Significant Changes in Pathogenicity. Veterinary Microbiology, 158, 291-299.

https://doi.org/10.1016/j.vetmic.2012.02.036

[6] Rowland, R.R., Kervin, R., Kuckleburg, C., Sperlich, A. and Benfield, D.A. (1999) The Localization of Porcine Reproductive and Respiratory Syndrome Virus Nucleocapsid Protein to the Nucleolus of Infected Cells and Identification of a Potential Nucleolar Localization Signal Sequence. Virus Research, 64, 1-12. https://doi.org/10.1016/S0168-1702(99)00048-9

[7] Pol, J.M., van Dijk, J.E., Wensvoort, G. and Terpstra, C. (1991) Pathological, Ultrastructural, and Immunohistochemical Changes Caused by Lelystad Virus in Experimentally Induced Infections of Mystery Swine Disease (Synonym: Porcine Epidemic Abortion and Respiratory Syndrome (PEARS)). Veterinary Quarterly, 13, 137-143. https://doi.org/10.1080/01652176.1991.9694298

[8] Wongyanin, P., Buranapraditkul, S., Yoo, D., Thanawongnuwech, R., Roth, J.A. and Suradhat, S. (2012) Role of Porcine Reproductive and Respiratory Syndrome Virus Nucleocapsid Protein in Induction of Interleukin-10 and Regulatory T-Lymphocytes (Treg). Journal of General Virology, 93, 1236-1246. https://doi.org/10.1099/vir.0.040287-0

[9] Fan, B., Liu, X., Bai, J., Li, Y., Zhang, Q. and Jiang, P. (2015) The 15N and 46R Residues of Highly Pathogenic Porcine Reproductive and Respiratory Syndrome Virus Nucleocapsid Protein Enhance Regulatory T Lymphocytes Proliferation. PLoS ONE, 10, e0138772. https://doi.org/10.1371/journal.pone.0138772

[10] Li, J.D., Yin, Y.B., Guo, B.Q., Zhou, S., Zhang, Y., Liu, X.C. and Sun, T.T. (2012) Sequence Analysis of the NSP2, ORF5, and ORF7 Genes of 11 PRRS Virus Isolates from China. Virus Genes, 45, 256-264. https://doi.org/10.1007/s11262-012-0763-4

[11] Shi, M., Lam, T.T., Hon, C.C., Murtaugh, M.P., Davies, P.R., Hui, R.K., Li, J., Wong, L.T., Yip, C.W., Jiang, J.W. and Leung, F.C. (2010) Phylogeny-Based Evolutionary, Demographical, and Geographical Dissection of North American Type 2 Porcine 
Reproductive and Respiratory Syndrome Viruses. Journal of Virology, 84, 8700-8711. https://doi.org/10.1128/JVI.02551-09

[12] Gou, Z.H., Chen, X.X., Li, R., Qiao, S.L., Guo, J.Q. and Zhang, G.P. (2018) The Prevalent History and Current Status of Porcine Reproductive and Respiratory Syndrome in China. Chinese Journal of Animal and Veterinary Sciences, 49, 1-9.

[13] Rovira, A., Reicks, D. and Muñoz-Zanzi, C. (2007) Evaluation of Surveillance Protocols for Detecting Porcine Reproductive and Respiratory Syndrome Virus Infection in Boar Studs by Simulation Modeling. Journal of Veterinary Diagnostic Investigation, 19, 492-501. https://doi.org/10.1177/104063870701900506

[14] Yoon, S.H., Song, J.Y., Lee, C.H., Choi, E.J., Cho, I.S. and Kim, B. (2008) Genetic Characterization of the Korean Porcine Reproductive and Respiratory Syndrome Viruses Based on the Nucleocapsid Protein Gene (ORF7) Sequences. Archives of Virology, 153, 627-635. https://doi.org/10.1007/s00705-007-0027-0

[15] Wootton, S.K., Nelson, E.A. and Yoo, D. (1998) Antigenic Structure of the Nucleocapsid Protein of Porcine Reproductive and Respiratory Syndrome Virus. Clinical \& Diagnostic Laboratory Immunology, 5, 773-779. https://doi.org/10.1128/CDLI.5.6.773-779.1998

[16] Rowland, R.R., Schneider, P., Fang, Y., Wootton, S., Yoo, D. and Benfield, D.A. (2003) Peptide Domains Involved in the Localization of the Porcine Reproductive and Respiratory Syndrome Virus Nucleocapsid Protein to the Nucleolus. Virology, 316, 135-145. https://doi.org/10.1016/S0042-6822(03)00482-3

[17] Dingwall, C. and Laskey, R.A. (1986) Protein Import into the Cell Nucleus. Annual Review of Cell Biology, 2, 367-390.

https://doi.org/10.1146/annurev.cb.02.110186.002055

[18] Atasheva, S., Fish, A., Fornerod, M. and Frolova, E.I. (2010) Venezuelan Equine Encephalitis Virus Capsid Protein Forms a Tetrameric Complex with CRM1 and Importin Alpha/Beta That Obstructs Nuclear Pore Complex Function. Journal of Virology, 84, 4158-4171. https://doi.org/10.1128/JVI.02554-09

[19] Pryor, M.J., Rawlinson, S.M., Butcher, R.E., Barton, C.L., Waterhouse, T.A., Vasudevan, S.G., Bardin, P.G., Wright, P.J., Jans, D.A. and Davidson, A.D. (2007) Nuclear Localization of Dengue Virus Nonstructural Protein 5 through Its Importin Alpha/Beta-Recognized Nuclear Localization Sequences Is Integral to Viral Infection. Traffic, 8, 795-807. https://doi.org/10.1111/j.1600-0854.2007.00579.x

[20] Lee, C., Hodgins, D., Calvert, J.G., Welch, S.K., Jolie, R. and Yoo, D. (2006) Mutations within the Nuclear Localization Signal of the Porcine Reproductive and Respiratory Syndrome Virus Nucleocapsid Protein Attenuate Virus Replication. Virology, 346, 238-250. https://doi.org/10.1016/j.virol.2005.11.005 